\title{
Coronavirus and State Actions: Questions By and For Policy Planners and Analysts
}

\author{
Dikeos CG* \\ Department of Political Science, Democritus University of Thrace, Greece
}

*Corresponding author: Costas G Dikeos, Department of Political Science, Democritus University of Thrace, Komotini, Greece; Email: cdikeos@polsci.duth.gr

\section{Editorial}

Volume 3 Issue 2

Received Date: March 24, 2020

Published Date: April 06, 2020

DOI: $10.23880 /$ jqhe-16000156

\section{Editorial}

The coronavirus outbreak and crisis has a wide range and multiplicity of repercussions, not just medical, but also social (loss of loved ones, mourning, bereavement, isolation), economic (activity restrictions, sales down-turn, company close-downs, loss of productivity combined with sickabsence payments), and political (postponing elections).

In a nutshell the coronavirus has a considerable (albeit not tragically high especially when compared with other epidemics and pandemics in human history) cost. It seems (or at worst is) highly contagious, it will most probably put health provision in great stress, as numbers of diseased and deaths will rise, negatively affecting therapy of others too. It will also increase the need for isolation wards, and last but not least will put pressure to personnel alongside personnel's absence due to infection itself too.

Addressing and combating both the disease and its repercussions has now on moved to state decision making level, as governments seek immediately applicable solutions which (solutions) cause further disruption (hopefully not as harmful as inaction from the policymakers side).

Laws and emergency decrees, therefore, attempt combating both the spreading of the disease -and reducing/ containing the number of new cases-, alongside facilitating treatment on the one hand, and limiting economic and social consequences on the other. In this sense emphasis is given to monitoring, hygiene, quarantine, and restrictions in moving around, gatherings etc, reduction and observation of social contacts, whilst some of these policies are affecting negatively economic activity (eg restaurants, cinemas, mallmarkets, retail shops, even in some cases factory closures).

We are therefore faced with -or even indeed 'confronted by'- a new form of an old question, that has now on taken the shape of challenge or even predicament. Though the old ('Lasswell-ian') definition of politics is (little paraphrased) 'who takes what from whom, when, and under what circumstances' is always present, decisions in times of crisis are even harsher and more pressing. A vast spectrum and array of interests are currently at stake. It has become a matter of politics and political argumentation for the making of public policy. Obviously the role of pressure groups and interest groups can be key in the process. However, it looks like that governments under extreme pressure make up their minds listening to other stakeholders (in this case medical experts) more carefully, whilst ideological arguments play their role too, however subtle and latent these arguments may be in the setting of restrictive rules and regulations as previously referred.

Such rules and regulations are imposed as to achieve disease containment. But at the same time they inhibit and restrict, setting limitations to commerce and moreover (as far as a political understanding of the state-citizen relation is under question) individual rights and liberties. The question thus becomes whether (and if yes at what level) these state actions are legitimate and ethically and politically justified. In other, it becomes an issue of (political) analysis of policy and social planning, as to reflect, reassess and comment upon.

Examining disease containment through the lens of health policy makes us think of primary health care prevention; there is little difference whether we approach vaccination (to which someone may disagree) as insulation not of the person vaccinated but of the people around him/ her on the one hand, and restriction of movement as to protect spreading of disease on the other, as in both cases one can observe interference with personal activity or with the realm of the individual and the individual's scope of activity(-ies) or even body. Such measures (especially incomers containment 
or quarantine, expulsion and/or isolation of the diseased in "lazarettos"). In other, it becomes a question whether primary health prevention may interfere with personal activity, scope of actions, and liberty of the individual, alongside economic repercussions it may cause, as to protect not only him (or her), but others. It ends up therefore to a dual question related firstly to individual-society-state relationship (viz. at the end of the day state power to order), and secondly (but not less importantly) legitimation of this state power.

The first question can be answered by rereading J. S. Mill's 'On Liberty' clearly stating that the only reason we can be justified to restrict an individual's scope of activities is protection of others, whilst the welfare of the individual under question is not a justification strong enough. Therefore compulsory in-home-lock-down as in Greece, or restriction of social groupings and gatherings to a maximum of two as in Germany can be in liberal terms legitimate only as protection of third parties, as can be said for compulsory vaccinations something some libertarians also agree with. The key issue is that the individual -in Mill's argument that this paper wishes to relay- has to succumb or obey for the benefit of others and not harming them.

However, how can we as a society, or indeed as individuals, accept powers restricting our liberties even if in principle we agree with Mill's argument? Or to put it in other terms under what circumstance and at what point is the state allowed to exercise force, oppression, power, authority etc? When can such state action be accepted? An approach to Weberian theory could in this case be particularly useful. Though the predicament of the multiplicity of terms (moreover if we think of it taking into account different languages) such as power, might, force, authority (and pouvoir, macht etc) should not be underestimated and overlooked, the paper wishes to focus on Weber's ideal type of rationally legitimized 'macht'. That is accepting and following orders because of trust to the process they were taken and to the knowledge, expertise and rationality of the decision maker and giver of the order. Here comes the dual meaning of the term 'authority' (in depth knowledge and ability to exercise power and direct actions of others). Weber, as known, in his ideal type of rational legitimation refers to the combination of the two.

Returning to our initial question of government imposed policies (and in that matter restrictions) the paper wishes to argue that these restrictive policies should be based upon experts' knowledge of epidemiology, disease spreading, immunology, therapy techniques and possibilities, etc., alongside the best possible assessment of the situation. It thus becomes an issue of using medical 'auctoritas' as to impose restrictions and dictate activities, i.e. to rule. Such an approach could lead to hazards of experts controlling lives of individuals and groups, if not society itself, therefore give rise to critiques related to 'medicals dictatorship' to borrow B. Kouschner's term. A proper response to this is that medical personnel when asked to be involved in policy planning during crises have to be self-restrained, use their expertise with view to common good, and within limits of 'guidance' rather than 'dictating', understanding that their actions are at the end of the day fully political.

Governments, supra-governmental and intragovernmental agencies alongside the World Health Organization must take into account medical knowledge and expertise, transform it to legislation and policy (including restrictive measures) and present/project it to citizens and population.

To conclude and recapitulate, governments and all policy makers should continue arguing, even more vigorously, for restrictive primary prevention, till vaccination (that is another form of primary prevention) is discovered (alongside the discovery of new and effective therapeutical methods). However they also have to withhold as guiding principles the combination of targeted limits to individual liberties (J. S. Mill) as to prevent harm to others, alongside M. Weber's idea (or indeed ideal type) of rational legitimation of power, based upon 'auctoritas' (in depth knowledge) so that the dual sense of authority (knowledge and 'macht' of might to impose) are combined for the benefit of all. This will make restriction more acceptable and the way out of current predicament easier and more certain.

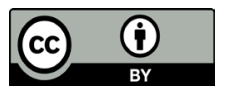

